\title{
Power, agency and middle leadership in English primary schools
}

Hammersley-Fletcher, Linda (Manchester Metropolitan University)

and

Michael Strain (University of Birmingham)

Hammersley-Fletcher, L. and Strain, M. (2011) "Power, agency and middle leadership in English primary schools" British Educational Research Journal 37, 5, 871-884;

DOI: $10.1080 / 01411926.2010 .506944$ 


\begin{abstract}
:
English primary schools are considered quasi-collegial institutions within which staff communicate regularly and openly (Hammersley-Fletcher and Kirkham, 2007). The activities of staff, however, are bound by institutional norms and conditions, and by societal expectations. Wider agendas of governmental control over the curriculum and external controls to ensure accountability and learning standards have influenced the development and purposes of middle leaders' roles. This is a conceptual paper that explores issues around the agency of primary school middle leaders within a wider context of the political and educational agenda. Through a reconsideration of research conducted by one of the authors since the inception of the notion of 'subject leaders' we exemplify ways in which primary school middle leaders' attitudes have developed and changed over the past fifteen years. In this paper we identify attitudes to leadership, the influence of distributed leadership on primary school role-holders and possible ways forward for middle leaders.
\end{abstract}

\title{
1. Introduction
}

This article seeks to explore how the roles of primary school middle leaders have developed and altered over the past 15 years. We draw on data gathered by one of the authors in three separate research periods between 1996 and 2007 and use these in conjunction with the literature to examine changing perspectives and perceptions of teacher leadership in a context of an increasingly pervasive preoccupation with accountability. We consider the extent to which middle leaders in primary schools exercise agency or are merely acting as agents of government change. Further, we begin to identify possible ways forward for middle leadership that could expose new relations of agency and constraint among UK primary school teachers.

In section 2 we outline how definitions of educational leadership have been contested within the literature and how concepts of distributed leadership have come to prominence. In section 3 we examine the changes that have taken place in schools related to the development of formal 'middle-leadership' roles. Section 4 then explores consequences for teacher agency arising from the tensions in the ways power and agency are mutually implicated and sensitive to changes in government policy. In section 5 we consider data collected from three time periods between 1996 and 2007. Data are presented which relate to the experiences of middle leaders in primary schools and used to identify ways in which their leadership roles have shifted. Finally we conclude by arguing that middle leadership acts as a mechanism for ensuring compliance with the government's agenda which may act to suppress dissent and impede recognition that real power remains located at the top.

\section{Conceptions of Leadership}

An extensive literature reveals leadership to be a highly contested concept open to a variety of definitions. Numerous recommendations in support of a variety of styles or approaches to leadership are to be found. For example in 1978 MacGregor Burns argued that "leadership is one of the most observed and least understood phenomena on earth" (p. 2). Cuban (1988) defines leadership as "influencing others' actions in achieving desirable ends" (quoted in Bush, 2003, p. 9). Yet a seemingly benign suggestion that leadership involves a process of influence between leader and follower (Yukl, 1998) is not left unchallenged. Depicting particular 'types' of leader as 'saviours' is a current trend according to Collinson (2005). He argues that leaders are presented alternatively as hero or villain. Some ideological and educational implications of creating a leadership, rather than a 'management' discourse and the conceptual and linguistic hallmarks of the two, are explored in Strain (2009). The burgeoning literature advising leaders to become 'excellent' tends to exaggerate what leaders 
themselves can achieve. Alongside this there has been a movement to encourage nonhierarchical and inclusive models of leadership, resulting in an emphasis on 'distributed leadership', encouraging more reciprocity among colleagues. Leadership can thus be viewed as a relational, fluid, multi-directional (Gronn, 2000) dimension that can empower workers, a relation described by Collinson (2005) as dialectical.

In England, distributed leadership was a term adopted and arguably adapted from notions of 'distributive' leadership by the National College for Leadership of Schools and Children's Services (formerly NCSL). The college, a government funded body developed to promote leadership in schools with the aim of raising standards of attainment and standards of teaching and learning, found that schools were somewhat resistant to notions of multiple leaders. Schools saw the move initially as divisive and associated leadership with hierarchy (Hammersley-Fletcher and Qualter, 2009). There was a need to re-frame the notion of leadership. In consequence former expectations of one leader taking full responsibility were replaced by arrangements whereby a distributed leadership could facilitate staff working together, taking responsibility for particular initiatives and periodically working as a leader for limited periods and purposes. Distributed leadership is a condition of creating group rather than individual action (Bennett et al., 2003; Woods et al., 2004). This means that senior staff must entrust others and create a culture of openness where individual expertise is recognised and individuals are empowered. The culture of distributed leadership accordingly develops from within. Distributed leadership envisages the development of shared contexts and overlapping roles to promote learning and leadership capacity (Grint, 2005). Grint goes on to explain that this model of leadership draws on the unique skills of people within the organisation and allows them to act flexibly, taking on leadership and working on tasks as and when appropriate, reverting to a non-leadership role when the task is complete. Spillane (2006) identifies leadership roles where several agents work in concert to direct a range of organisational projects and purposes. Harris (2008) argues that distributed leadership can be a vehicle for knowledge creation, sharing and mutual learning through school-to-school networks and the establishment of professional learning communities within and between schools. As Leithwood and Reihl (2003) argue, "teacher leaders can help other teachers to embrace goals, to understand changes that are needed to strengthen teaching and learning and to work towards improvement" (p. 3). This captures important requirements where there is a need to utilise a range of staff in a context of mandated reforms which head teachers may find impossible to manage on their own (Hatcher, 2005).

The notion of developing school middle leaders as a concerted force for change is an attractive one. It appears to challenge traditional assumptions of leadership as a configuration of hierarchical relations and has proved appealing to schools, especially to primary schools, where collegiality tends to be practised informally and collaboration is more routinely an organisational necessity (Hammersley-Fletcher and Kirkham, 2007). In research reported by Hammersley-Fletcher and Brundrett, (2005), all head teachers claimed to be acting within a distributed leadership framework, although evidence provided by their staff appeared to contradict this. Yet the idea of distributed leadership as an inherent organisational good can readily be challenged. As Blasé and Blasé (1999) warn, shared forms of governance may also allow leaders to control staff at a more subtle level. For example, having a particular group of teachers making decisions can be another form of control, less visible because it creates a feeling of teacher involvement. Intuitive or dispositional beliefs in the value of embracing change and developing teaching and learning might also induce greater readiness to compromise on quality where agendas are developed externally to the organisation. Wright (2003) points out, that collaborative models of leadership may ignore some of the tensions 
facing school leaders who have to negotiate a way forward in the light of OfSTED views about their effectiveness, performance tables and government programmes and advice. Moreover relatively informal leadership styles can mask opportunities for external agencies to secure implementation without adequate prior discussion, adaptation and iterative review. As Gold et.al. (2003) seem to suggest, in order for distributed leadership to be successful the head tended to act as the key source of initiatives and development. This view would seem to reduce the role of middle leaders to that of administrators or strategists within a vision that is the responsibility of the head. The formality of appointment to a leadership role does not automatically confer the associated and necessary authority and respect. Hatcher (2005) argues that "Government education policy does not rely primarily on headteachers' exercise of transformational leadership skills to secure the commitment of teachers through distributed leadership" (pg 254). Compliance, he argues, is secured through performance-management and extensive regulation, irrespective of teacher commitment. Thus a notion of distributed leadership which engages models of leadership that are multi-level and actively democratic is in direct tension with policy agendas imposed through a hierarchical educational structure (Hatcher, 2005).

\section{Changing relations in the school:}

Educational reform has been a significant area of government policy among industrialised nations for more than two decades (Levin, 2005). Brighouse (1997) recommended that in schools, all those with posts of responsibility should have some share in leadership, actively contributing to the schools vision. This notion was formalised in England in 1998 when the Teacher Training Agency (now Training and Development Agency) encouraged schools to re-designate curriculum coordinators as subject leaders. The aim of the TTA requirements was to support governmental drives for school improvement through improving professional development and the quality of teaching, leadership and consequently pupils' learning. Featherstone (1996) argued that Subject Leaders should be clear about the purposes of the school as well as their curriculum subject. The notion that there might be a role for leaders below the position of head teacher and deputy head teacher represented something of a culture shift, especially for the primary school (Hammersley-Fletcher, 2002). Furthermore, Hammersley-Fletcher argued that the high stakes associated with learning outcomes in the newly imposed national literacy and numeracy curriculum led to primary schools identifying senior management teams consisting of the subject leaders with responsibilities for leading these 'core' curriculum subjects, core subject leaders being viewed as senior to other curriculum leaders. Furthermore, because primary schools have tended to be smaller organisations than secondary schools, many primary schools gave some curriculum responsibility to their entire staff (with some holding multiple responsibilities). Thus, in some cases all teaching staff in a school could have been allocated a middle leadership role.

This new focus on middle leadership together with the stress on efficient management, school improvement, and on the principle of allowing educational change to be shaped more directly by market forces, created divisions among staff. Leadership was emphasized at the expense of other discussions about school organisation. Caldwell (1997) has seen these changes as unavoidable, part of a set of 'mega-trends' that will persist and which are likely to enforce increased system efficiency and school productivity. Fullan (2003) however, has commented,

"England brought about large-scale improvement in literacy and numeracy in 20,000 primary schools during the period 1997-2002. School leaders played a key role in these impressive accomplishments, yet, in this same period, the morale of teachers and principals did not improve due to a 
number of complex factors: the overall pace of change, work overload, lack of ownership of the strategy, and so on..." (p. 27).

For Robertson (1996) this shift towards greater leadership has led teachers away from their primary professional tasks of defining and delivering educational goals and curricula. They are diverted to new technical tasks such as strategic planning and performance monitoring. These compliance procedures are now necessary to enable government to demonstrate efficiency and to service parents, who need information as a basis for 'choice' in the new quasi-market for schooling. Robertson calls these processes a 'proletarianisation of teachers' work...the result of the penetration of the commodity form into schooling and the labour process' (p.52).

Recent government strategies in England and Wales have attempted to reduce some of these pressures on teachers. The range and quantity of testing has been reduced, and initiatives such as 'Remodelling the School Workforce' and the 'Extended Schools' agenda have sought to shift the ways in which schools operate to include a greater range of 'non-teachers' in learning and teaching. For example, beginning in 2003, workforce remodelling claimed to provide opportunities for all staff to get involved in setting school wide agendas aimed at promoting learning for all within the school community. This agenda was hailed as offering schools freedom from the centralised models of the recent past by handing control back to the schools themselves (Hammersley-Fletcher and Adnett, 2009). In this way, it could be argued that teachers were given opportunities to recapture local educational agendas. Gunter (2007) however argues that remodelling operates to distance teachers from the classroom, using allocated time designing schemes for others (i.e. non-teachers) to implement, whilst their own classes were taken by less well paid non-teachers. Certainly such initiatives have provided a framework for continuous functional adjustment among teachers' professional and operational roles and, though less overtly, acted as a vehicle for a significant redistribution of power (Hartley, 2007). Agency, as Giddens has so lucidly explained (1998) is an elemental basis of power. Equally, agency presumes a context of constraints.

\section{Teacher agency}

Barber (2005) controversially argues that teachers have moved from a stage of 'uninformed professionalism' prior to the 1980s, when teachers lacked knowledge, skills and attitudes appropriate for a new century, to a stage of 'informed prescription' where these skills have been developed and governments can now allow teachers a degree of licensed autonomy. Whilst there are debates about this view of teacher development, what is clear is the level of control Barber attributes to the state. Whitty (2006) also argues that the characteristics of a professional are increasingly determined by the state. Therefore significant questions arise about how power redistributions change professional relations and how working relations may in their turn affect schooling outcomes.

Bourdieu's account of 'habitus' provides us with useful elements that support a theory of agency in institutional settings. The concept may be used to map those relational properties by which Bourdieu and others have explained the formation and operation of norms and practices among particular social classes and groups (Bourdieu and Passeron, 1977), 'Habitus' supplements our understanding of structural relations by its analytical representation of the 'system of dispositions' that induce an agent to act and respond in particular ways in a given setting. A leader in a leadership role at any level in a school or 
other organisation acts at points of intersection between his/her own history as a person and the history of the institution made evident in the school's distinctive 'culture'. Bourdieu can thus claim that for each agent, 'the principle of action...is neither a subject confronting the world as an object in a relation of pure knowledge, nor a 'milieu' exerting a form of mechanical causality on the agent' (2000, p. 150). Leaders neither lead, nor are they led entirely. Leadership is neither a determining origin of the outcomes of institutional policies and actions, nor is it itself determined by the prevailing set of potentialities and customs exerted formatively by others, whether the 'led' or the 'co-leaders'.

In this analytical framework agency is both enabled and limited by prevailing dispositions of power. These ideas can help inform our thinking about the ways in which primary school middle leaders have reacted to and developed practices within what Gunter (2001) describes as a predominantly neo-liberal political agenda for education. Whilst individuals may feel authorised to implement their own decisions, needs and desires, their agency is in reality constrained by the less visible structures and rules constructed within wider agendas which, in their turn, influence the cultural norms and practices of society and the institutions within which they operate. In this way teachers may be placed in a position where their actions and priorities are heavily influenced by wider political agendas and sectoral interests. For example, work by Forrester (2005) indicated that school leaders were more anxious to do a good job as judged by inspection findings than to ensure positive experiences for all the children that they teach. This is not to say that this is true of all teachers, or that teachers don't believe in the importance of developing a good educational experience that will benefit all children. But the example also reveals the pressures that a regime of public accountability and a predominantly consumerist model of society (Patterson, 2000; Hatcher, 2005) place upon teachers.

It is important to recognise that change cannot be wholly under the control of any person or body. Thus, whilst governments can legislate or advise on change, the outcomes may not be those predicted (Newman, 2001). Mention has already been made of some resistance to advocacy of devolved leadership in primary schools, until the concept was re-formulated as a move towards distributed leadership - an apparently collaborative model of leadership that sat more comfortably with primary teachers' understanding of how schools as organisations do, and should, behave. As the educational environment has changed, so too have the behaviours and attitudes of school middle leaders. Isomorphism describes the ways in which organisations adapt to a changing environment and changing expectations about appropriate and desirable practices (Newman, 2001). It is important to adapt, in order to gain legitimacy. Thus in an environment of sustained public criticism of schools and teachers, schools adapt and reconfigure relations with the prevailing policy environment so as to demonstrate their professional competence and reliability. DiMaggio and Powell (1991) suggest that isomorphism can occur in one of three ways. Coercive isomorphism occurs where the state obliges an organisation to change. Here legislation prescribes school practice authoritatively. Mimetic isomorphism refers to situations where one organisation imitates the practices of another, widely perceived to be successful. For schools, success is identified in test results and inspection findings, so less successful schools are likely to adopt practices regarded as instrumental in securing success in other, more successful schools. Normative isomorphism describes the behaviour of a school that purposefully adopts externally defined professional norms, defining, for example what it is to be a middle leader in a primary school. Thus, as Currie et al. (2005) argue, the degree to which schools can take a risk is limited since each of these dimensions of power exert influence on and constrain agency within the school 
organisation through vertically configured and hierarchically ordered lines of control despite prevailing rhetoric about the desirability and value of distributed leadership.

\section{Stories from middle leaders}

In this section we draw on the research of the first named author to illustrate 1) the middle leadership role; 2) the rise of distributed leadership practices; and 3) a period of change when leadership roles are being re-considered in the light of workforce remodelling.

1996-9: This sub-section draws on PhD research (XXXX). Twenty primary school curriculum co-ordinators from ten schools took part in semi-structured interviews across two English Local Authorities. This was a period when the TTA was introducing the principle of subject leadership as part of the introduction of a national curriculum for literacy and numeracy. Responses tell us something about how these developing middle leaders viewed their roles and what issues were of importance to them at that time. Roles mainly centred on providing subject knowledge and resources for colleagues.

...advice and helping people and taking lessons and getting equipment out for other people and things like that... (p.151)

Support for the notion of providing subject expertise and practical support was very strong. There was, however, an expectation that leaders would also monitor colleagues work in their area of curriculum responsibility. Whilst they were aware of this role, there was a lot of sensitivity about going into others' classrooms and monitoring teacher activity, so the middle leaders interviewed had opted for looking at children's work as a preferred method of monitoring standards. These middle leaders talked a lot about leading by example rather than imposing their own practice upon others, and hoped that they would gain support through demonstrating enthusiasm for the subject. For those teachers who had gained a curriculum responsibility that they would not have chosen and which was not an area of expertise, this was more challenging, as they had to develop their knowledge of the subject. The middle (subject) leaders also voiced objections to being labelled as a leader. Thus, in order to cope with their new leadership roles some teachers interviewed commented that they liked to have a senior manager tell staff that change was necessary so that they could then suggest what that change might be, without appearing to be the initiator or enforcer of the change.

[I prefer]...somebody in senior management actually making the whole thing more formal and then it's not really me forcing my views of what I think we should be doing on everybody else (p.184)

Another way of engaging colleagues in change was to suggest and discuss developments in staff meetings. This was by far the most popular way of introducing change and most readily allowed staff to behave in a collegial and collaborative way. The middle leaders also expressed their concerns about areas of the curriculum being identified as 'core provision', and so becoming a focus of attention, because of the negative impact that this may have on other curriculum areas. One history subject leader was distressed that she had spent a lot of time working on the history curriculum and was now meeting resistance from staff who were prioritising the new literacy curriculum changes. What was also clear was the power of the head teacher to agree to or reject their ideas and suggestions for development. "The teachers make requests and then the head tries to accommodate them...by allowing staff meetings or I suppose by putting it in the school development plan" (p. 213). Action was very much in the gift of the head; the head could choose what subjects to prioritise and which approaches to 
adopt. The middle leaders felt this to be entirely appropriate as the head was after all in charge of the school and held the final responsibility.

2002-4: This sub-section reports research on Primary School Middle Leadership commissioned by the NCSL (xxx). The paper draws on the forty-four semi-structured interviews conducted with middle leaders in twenty-two primary schools. Twenty-four interviews were carried out across four English Local Authorities and the final twenty all belonged to a sample of NCSL volunteer schools and were therefore representative of a range of schools across England. The significant difference between this and the previously reported research was the growing focus on the notion of distributed leadership. The head teachers talked directly about shared and distributed leadership (mimetic isomorphism), whilst the middle leaders talked about their growing leadership confidence and potential (normative isomorphism) as this middle leader indicates.

I think my natural style is to discuss issues and manage as often as possible by consensus. In this role, I have learned to be more of a leader by stating requirements clearly. I am very proud of my work. I am proud to see my ideas implemented and improving the climate of our school. (p. 11)

The emphasis was very much on making change through consensus, with one or two middle leaders talking about initiating change by recruiting a reluctant member of staff to pilot new practices, on the basis that if you could convince a difficult member of staff, the rest would be easy. They emphasised the importance of teamwork.

...working together as a team, building up good teamwork skills so that one person isn't just 'oh follow me I'm the leader' but 'come on we can all work together on this so I think that's important. (p. 11)

Working collaboratively with colleagues was still a strongly emphasized quality, but whether practice actually reflected what was still at that time, rather a confused definition of distributed leadership, is open to question. References to 'consensus' also exposed a more worrying edge. Stories of non-conforming teachers who had left, or been given roles where they had little influence on others, were mentioned in four schools.

Nevertheless whilst still often referred to as curriculum co-ordinators rather than subject leaders, these middle leaders saw themselves as holding a leadership role. It became clear, however, that they were doing much the same as they always had done with slightly more emphasis on the monitoring aspects of the role. Some schools were now conducting peer review of teaching but this was still at a very modest level, with most monitoring being conducted through the review of children's completed work. The importance of subject knowledge was still emphasized, so that middle leaders could act as a guide and mentor within their curriculum subject area. It was again clear that their ability to be innovative and instigate change was very dependent upon the head. On the whole they were acting to implement government agendas, albeit unquestioningly, with perhaps some modifications, rather than generate new practices of their own.

...I need to be a channel through from the authority or the government where the initiatives are coming from, a resource provider, a facilitator in the broadest sense really, to make sure that my subject is being delivered to the highest standard it can be... (p. 26) 
There were also indications that being a core subject leader meant you were more likely to gain the support of colleagues (which justified the concerns expressed in the earlier study above) and be on the senior management team. "I've gone, from a fairly minor subject as viewed by most people to a core subject. My role has actually changed quite a lot because people are very receptive to literacy because they're all doing it every single day" (p. 30). This notion that the agency enjoyed as a middle leader is dependent upon an externally authorised emphasis on your subject area supports the view that middle leadership is more complex and elusive than implied by the mere conferment of a title on a teacher. Leadership potential in the designated role derives crucially from the political agenda pursued outside of the school.

2004-7: This section reports data collected on three occasions (xxx Workforce Remodelling in Schools: working through the change agenda; $x x x$, Workforce Remodelling in Schools: engaging in the change agenda; $x x x$, Workforce Remodelling in Schools: management of change) from middle leaders as part of reflection on the changes engaged upon after introduction of the school workforce remodelling agenda. Nine primary middle leaders from nine primary schools were interviewed from two Local Authorities. Here, initiating significant change appeared to dominate the now established middle-leadership roles, with either senior management teams deciding upon ways forward or, alternatively, the whole staff being consulted. The focus on consultation was a significant feature of all three reports. There was undoubtedly a lot of discussion around changes being adopted and the middle leaders consulted felt fully engaged and involved in initiatives. When asked about instigating change however, it seemed that in most cases the head was still clearly and ultimately in charge of any significant shifts, albeit with consultation.

... setting the agenda I think comes from the top from the headteacher. And I think one of the strengths of this school is that [the head] had done a lot of making sure the teachers, you know, were on board and coming along with her... (p. 27 third report)

Consulting with and keeping staff informed was regarded as good practice and seen as allowing schools to conform to government agendas. Within the remodelling agenda, the government had suggested that schools should develop a team which should include representatives from the whole school, as well as interested local bodies, so that locally based initiatives could be encouraged. This was not a part of the legislative provisions for the changes and where such teams were set up, they appeared mainly to look at ways of implementing the formal parts of the change process. Thus changes made appeared to be rather conservative in nature. One more significant element of the change process was the introduction of a $10 \%$ requirement for teachers to be released from the classroom to have an opportunity to plan, prepare and assess. Releasing primary school teachers from classrooms had the potential to cost schools with relatively small budgets a significant amount of money in supply cover. The government encouraged the use of teaching assistants to cover classes as a possible solution and had already introduced initiatives to develop and focus on this role. As a consequence, in the schools visited, teaching assistants were taking responsibility for whole classes, albeit for short periods and with particular forms of support to enable them to do this. This was receiving mixed support as some teachers saw this as a threat, others as a significant help. There were however those who expressed concerns about pay, exploiting the role played by the TA and about the extent to which a TA should be used. As one explained, 
I do very much keep in my head they are a teaching assistant, they're not there to do my job and I would never expect them to. I have heard of cases in other schools where that has happened and it astounds me, because to be quite honest with you that's not why they do that job and they certainly don't get paid to do that. But they are invaluable in the support that they do provide ... (p. 40, third report).

Middle leaders also expressed a concern to protect their subject responsibility in terms of standards: "I'm quite protective of those subjects cos I'm accountable at the end of the day" (p. 43 third report). Thus there was some uncertainty that teaching assistants could uphold the quality required to gain good subject related results, if over-used. The remodelling initiative had also led to a reconfiguration of leadership roles. In some schools the whole staff were involved in discussing and implementing the remodelling programme. In others the senior management team (which is some cases involved a senior level teaching assistant) led the change agenda. These data indicated that the role of middle leadership is still fluid, reforming and arguably seeking to give renewed emphasis to teaching, learning and management structures that effectively support the individual school.

\section{Conclusions}

Richmon (2006) recommends a move away from the "tired premise: the principal does... and the school improves." where "The fundamentals of administration are reduced to pulling levers and turning knobs" (p. 21). Instead it is important that schools acknowledge the chaotic environment within which they operate. Fielding argues that conceptual clarity and coherent arguments are vitally important. "Too often the best of what is intended is denied by poverty of thought and a surfeit of misdirected enthusiasm" (Fielding, 2007, p. 384). Primary school middle leaders have been subjected to a variety of political initiatives which define their role as one of leadership, specify in some detail what is expected of them and require them to transmit and deliver externally defined agendas for change. These measures appear so far to have redefined what it means to be a leader in a way that provides an alternative to the rigidities associated with hierarchical forms of leadership, but which does little to address primary school power relations in practice.

Wheatley (2005) argues that,

"Once we stop treating organizations and people as machines and move to the paradigm of living systems, organizational change is not a problem. Using this worldview, it is possible to create organizations rich in people who are capable of adapting as needed, who are alert to changes in their environment, who are able to innovate strategically". (p. 76)

It could be argued that the notion of middle leadership in the English primary school, as a structural principle that could embrace the totality of professional relations among the whole staff, was a flawed idea. The rationale supporting some form of distributed leadership was that different people might assume responsibility at different times for different things. It could, on the other hand, be argued that the label of leader runs counter to primary school traditions of informal collaboration and that such a move away from traditional notions of leadership was unsuited to the English primary school ethos. Bell and Ritchie (1996) argued that the advantage of developing subject leaders was to encourage those taking up a responsibility to be pro-active in developing their subject area. The evidence above would 
seem to suggest that successful middle leaders become efficient at creating new bases of evidence to demonstrate compliance and recognition in respect of implementing government policies and the head's agendas, rather than using their role to develop significant initiatives in learning and teaching practices. Thus it seems right to question the relevance and validity of current notions of multi-layered leadership. The notions that teachers need to be labelled 'leader' in order to be pro-active in their role is also open to question. If the aim of middle leadership is to foster creative practice, then time and space, in terms of both resources and institutionally located authority could be allocated to enable colleagues to discuss and debate practice in ways that seem most productive. Imposition of under-rationalised organisational formulae will confer on those institutions only pale and ineffectual 'images' of what is aimed for in terms of a difference in children's lives.

The question of the extent to which the principle of middle leadership represents an authentic innovation must be considered alongside the possibility that middle leaders have been created as a device to encourage compliance to externally driven agendas for change. It might be argued that middle leadership provides a potential solution to the need for a sustainable leadership recruitment pathway at a time of chronic shortage of headteacher supply. If this is so, these seemingly complex changes may simply cloak a story of 'smoke and mirrors' in which power still resides at the top of institutional hierarchies and delegation of power, as agency, remains minimal, a situation concealed by the delegation of an increasing range and number of relatively meaningless administrative tasks. We have found four cases where middle leaders did not comply with headteacher requirements, where either they left the school or they were side-lined. We see here evidence of coercive isomorphism operating in some primary schools, suppressing dissent within a prevailing culture of compliance and control. Conversely, mimetic isomorphism is also found, with many schools being encouraged to adopt similar solutions to those adopted by recently identified 'successful' schools.

Yet we should be careful not to dichotomize power and resistance, or 'hero-ise' followership as antagonistically related to leadership.

"Giddens's notion of 'the dialectic of control' holds that, no matter how asymmetrical, power relations are always two-way, contingent and to some degree interdependent."

Collinson, (2005) p. 1421

It is possible now to see more clearly the short-sightedness of some instrumental assumptions underlying simplistic 'one size fits all' models of leadership that have been consistently promoted by agencies such as the National College, in an attempt to define, legitimate, and disseminate particular leadership norms and practices in UK state schools. 


\section{References:}

Barber, M. (2005) The virtue of Accountability, Boston, MD: Boston University. Beck, J. (2008) Governmental professionalism: re-professionalising or de-professionalising teachers in England? British Journal of Educational Studies, 56 (2): 119-143. Bell, D. and Ritchie, R. (1999) Towards Effective Subject Leadership in the Primary School. Buckingham: Open University Press.

Bennett, N., Wise, C., Woods, P. and Harvey, J.A. (2003) Distributed Leadership, a review of the literature Nottingham: National College for School Leadership.

Blasé, J. and Blasé, J (1999) "Implementation of shared governance for instructional improvement; principals' perspectives'," Journal of Educational Administration 37 (5): 476500 .

Bourdieu, P. (1998) Practical Reason. Cambridge: Polity Press.

Bourdieu, P. and Passeron, J.C., (1977) Reproduction in Education, Society and Culture. London and Beverly Hills: Sage Publications.

Brighouse, T. (1997) "Leading and managing primary schools: the changing world of the local education authority" in Cullingford, C. The politics of primary education. Buckingham: The Open University Press

Bush, T. (2003) School Leadership: Concepts and Evidence. Nottingham: National College for School Leadership.

Caldwell, B.J. (1997) "Global trends and expectations for the future reform of school" in Davies, B. and Ellison, L. (eds) School Leadership for the $21^{\text {st }}$ Century London: Routledge Day, C. (2002) School reform and transitions in teacher professionalism and identity. International Journal of Educational Research, 37(8): 677-692. Collinson, D (2005) "Dialectics of Leadership" in Human Relations 58 (11): 1419-1442. Cuban, L. (1988) The Managerial Imperative and the Practice of Leadership in Schools, Albany, NY: State University of New York Press.

Currie, G., Boyett, I., \& Suhomlinova, O. (2005). "Transformational Leadership within secondary schools in England. A panacea for organizational ills?" Public Administration 83 (2): 265-296.

DiMaggio, P. and Powell, W. (1991) "Introduction" in Powell, W. and DiMaggio, P. (eds) The New Institutionalism in Organizational Analysis Chicago: University of Chicago Press Featherstone, S. (1996) "An inspector calls- the role of the curriculum co-ordinator in inspection" in O'Niell, J. and Kitson, N. (Eds) Effective curriculum management- coordinating learning in the primary school. London: Routledge

Fielding, M. (2007) "The human cost and intellectual poverty of high performance schooling: radical philosophy, John MacMurray and the remaking of person-centred education" Journal of Education Policy 22(4): 338-409.

Fullan, M. (2003) The moral imperative of school leadership Thousand Oaks, CA: Sage. Forrester, G. (2005) "All in a day's work: primary teachers 'performing' and 'caring"”, Gender and Education 17 (3): 271-287.

Giddens, A. and Pierson, C. (1998) Conversations with Anthony Giddens: making sense of modernity. Cambridge: Polity Press

Gold, A., Evans, J., Earley, P., Halpin, D. and Collarbone, P. (2003) "Principled Principals? Values-driven leadership: evidence from ten case studies of 'outstanding' school leaders", Educational Management and Administration 31 (2): 127-138

Grint, K. (2005) Leadership: Limits and Possibilities Basingstoke: Palgrave Macmillan. 
Gronn, P. (2000) "Distributed Properties: A New Architecture for Leadership" Educational Management and Administration 28 (3): 317-338.

Gunter, H. (2001) Leaders and Leadership in Education. London: Paul Chapman

Gunter, H. (2007) "Remodelling the School Workforce in England: a study in tyranny" Journal for Critical Education Policy Studies .5 (1): 1-11.

Hammersley-Fletcher, L. (2002) "Becoming a Subject Leader: what's in a name" School Leadership and Management, 22 (4): 407-420.

Hammersley-Fletcher, L. and Adnett, N. (2009) "Reassignment or Redefinition? Workforce Remodelling at the national and school level in England" Educational Management, Administration and Leadership 37 (2): 181-198.

Hammersley-Fletcher, L. and Brundrett, M. (2005) "Leaders on Leadership: the impressions of primary school headteachers and subject leaders" in School Leadership and Management 25 (1): 59-75.

Hammersley-Fletcher, L. and Kirkham G. (2007) "Middle Leadership in Communities of Primary School Practice: distribution or deception?" School Leadership and ManagementSpecial Edition 27 (5): 423-435.

Hammersley-Fletcher, L. and Qualter A. (2009) "Chasing improved pupil performance: the impact of policy change on school educators' perceptions of their professional identity, the case of further change in English schools" British Educational Research Journal, First published on: 24 September 2009 (iFirst)

Harris, A, (2008) "Distributed Leadership through the Looking Glass". Journal of Education Administration, Volume 46 (2): 1-3

Hartley, D. (2007) Education Policy and the 'Inter'-Regnum. Journal of Education Policy, 22(6): 695-708.

Hatcher, R. (2005) "The Distribution of Leadership and Power in Schools" British Journal of Sociology of Education, 26 (2): 253-267

Leithwood, K.A. and Riehl, C. (2003) What We Know About Successful School Leadership.

Philadelphia, PA: Temple University Press. Levin, B. (2005) Governing Education Toronto, ON: University of Toronto Press.

Newman, J. (2001) Modernising Governance: New Labour, Policy and Society London: Sage.

Patterson, L. (2000) Education and the Scottish Parliament, Edinburgh: Dunedin Academic Press.

Richmon, M. J. (2006) Phorsaking filosophy for the sake of school improvement: what could go wrong? Paper presented to the Leadership Study Forum of the York Region District School Board, Newmarket, Ontario, Canada.

Robertson, S. L. (1996) "Teachers' Work, Restructuring and Post-Fordism: Constructing the New 'Professionalism'” in Goodson, I. G., and Hargreaves, A. (eds) Teachers' Professional Lives, Routledge, pp. 28-55.

Spillane, J. (2006) Distributed Leadership California: Jossey-Bass.

Strain, M. (2009) Some Cultural and Ethical Implications of the Leadership 'Turn' in

Education. Educational Management, Administration and Leadership, 37.1: 67-84.

Wheatley, M. (2005) Finding our way: Leadership for an uncertain time San Francisco, CA:

Berrett-Koehler.

Whitty, G. (2006) "Teacher Professionalism in a New Era" General Teaching Council for Northern Ireland Annual Lecture, Queens University, Belfast $14^{\text {th }}$ March 2006.

Woods, P. A., Bennett, N., Harvey, J. A. \& Wise, C. (2004) "Variabilities and dualities in distributed leadership: findings from a systematic literature review" Educational Management Administration and Leadership 32 (4): 439-457 
Wright, N. (2003) "Principled 'bastard' leadership?" Educational Management and Administration 31 (2): 139-143

Yukl, G. L. (1998) Leadership in organisations Upper Saddle River, NJ: Prentice Hall. 